\title{
Comparison of colon adenoma detection rates using cap- assisted and Endocuff-assisted colonoscopy: a randomized controlled trial
}

\section{다(1)우우}

\author{
Authors

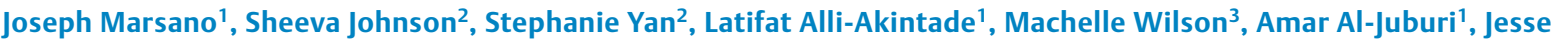 \\ Stondell ${ }^{1}$, Sooraj Tejaswi ${ }^{1}$
}

Institutions

1 Division of Gastroenterology and Hepatology, University of California Davis School of Medicine, Sacramento, California, United States

2 Department of Internal Medicine, University of California Davis School of Medicine, Sacramento, California, United States

3 Department of Public Health Sciences, Division of Biostatistics, University of California Davis School of Medicine, Sacramento, California, United States

submitted 15.12 .2018

accepted after revision 10.4.2019

Bibliography

DOI https://doi.org/10.1055/a-0996-7891 |

Endoscopy International Open 2019; 07: E1585-E1591

(c) Georg Thieme Verlag KG Stuttgart · New York

eISSN 2196-9736

Corresponding author

Sooraj Tejaswi, MD, MSPH, University of California Davis, Department of Internal Medicine, Division of Gastroenterology and Hepatology, 4150 V Street, Suite 3500, Sacramento, California 95817, USA

Fax: +1- 916-734-7908

stejaswi@ucdavis.edu

\section{ABSTRACT}

Objectives and study aim Colonoscopy prevents colorectal cancer by removing adenomatous polyps, but missed adenomas lead to interval cancers. Different devices have been used to increase adenoma detection rates (ADR). Two such devices of interest are the transparent cap (Olympus) and Endocuff (ARC Medical). Our study aimed to compare differences in ADR between Endocuff-assisted colonoscopy (EAC), cap-assisted colonoscopy (CAC) and standard colonoscopy (SC).

Patients and methods A sample size of 126 subjects was calculated to determine an effect size of $30 \%$. Patients undergoing screening or surveillance colonoscopy between March 2016 and January 2017 were randomized to SC, CAC or EAC groups. Three experienced endoscopists performed all colonoscopies. Patient demographics, procedure indication, Boston Bowel Prep Score (BBPS), withdrawal time, polyp size, location, histopathology, were analyzed.

Results There was no difference in ADR (52\%, 40\% and $54 \%)$ in the SC, CAC and EAC groups respectively $(P=0.4)$. Similar findings were also observed for proximal ADR $(45 \%$, $35 \%$, and $50 \%, P=0.4)$ and SSA detection rate $(16 \%, 14 \%$, and $23 \%, P=0.5)$. EAC detected higher mean ADR per colonoscopy compared to CAC ( 1.70 vs $0.76, P=0.01)$. However, there was no significant difference in mean ADR per positive colonoscopy $(2.08,1.63$, and $2.59, P=0.21)$.

Conclusion In a randomized controlled trial comparing $\mathrm{AC}$ to $C A C$ and SC, neither device conferred additional benefits in ADR among high detectors. When comparing each device, EAC may be better than CAC at detecting more total adenomas.

\section{Introduction}

Colorectal cancer (CRC) is the second leading cause of cancerrelated deaths in the United States [1]. Screening colonoscopy has reduced CRC mortality by removing adenomas [2 -4]. However, missed adenomas can lead to interval CRC [5].
Adenoma detection rate (ADR) is a quality measure of screening colonoscopy with higher rates associated with decreased interval CRC and mortality [6-8]. To increase polyp detection, different devices have been designed to stabilize the colonoscope tip, and flatten haustral folds to help detect flatter, subtler lesions [9]. Two such devices of interest are the transparent cap and the Endocuff. 
The transparent cap is a disposable, clear plastic cylinder that attaches to the colonoscope tip ( $\triangleright$ Fig. 1). Data comparing ADR between standard colonoscopy (SC) and cap-assisted colonoscopy (CAC) show modest improvement in some studies, and no difference in others [10-16]. Endocuff is a newer disposable device with soft projections that flatten the mucosal folds during withdrawal ( $\mathbf{F i g . 2}$ ). Since its inception, several studies have shown significant improvements in ADR when compared to standard colonoscopy [17-19].

In the current study, we aimed to compare differences in ADR between Endocuff-assisted colonoscopy (EAC), CAC and SC. To the best of our knowledge, this is the first study to compare these distal attachments with each other.

\section{Patients and methods}

\section{Study design and patient population}

This was a single-center, randomized, controlled trial. The study was approved by the University of California, Davis Institutional Review Board (study no. 797109-7 approved 1/7/2016). The study was registered on clinicaltrials.gov (NCT02665741). Patients aged 50 years or older scheduled to undergo average risk screening or surveillance colonoscopy at the UC Davis primary care network (PCN) clinic endoscopy suites between March 2016 and January 2017 who met eligibility criteria based on chart review were contacted prior to their procedure day and informed about the study. Exclusion criteria were: age $<50$ or $>85$ years, personal history of CRC, inflammatory bowel disease, family history of CRC in a first-degree relative younger than age 60 , personal or family history of hereditary polyposis syndromes such as Lynch syndrome or familial adenomatous polyposis syndrome, pregnancy, current incarceration, inability to consent, suspicion of CRC based on noninvasive testing such as stool tests for hemoglobin or DNA, imaging finding suggestive of CRC, and patients undergoing diagnostic colonoscopy for evaluation of any gastrointestinal symptoms or signs.

Patients interested in the study received the study consent form via secured electronic medical record message or letter. After discussion with the endoscopist on the day of the procedure, patients agreeable to proceeding with the study provided written consent. Prior to patient recruitment, a randomization schedule was created using the random number generator in Excel, which assigned equal numbers of patients to each endoscopist. Each of the three endoscopists' schedule contained a unique, random, and numbered order of interventions totaling 42. The endoscopist assigned patients sequentially to either SC, EAC or CAC arms based on the randomization schedule. Study participants were blinded to the intervention.

\section{Procedure}

Patients received split-dose polyethylene glycol bowel preparation. All procedures were performed using Olympus 180 highdefinition white light colonoscopes (Olympus Medical Systems, Tokyo, Japan) under conscious sedation with midazolam, fentanyl or meperidine, with some patients getting diphenhydramine and/or promethazine as adjuncts. Three experienced endoscopists performed all colonoscopies. Based on patient

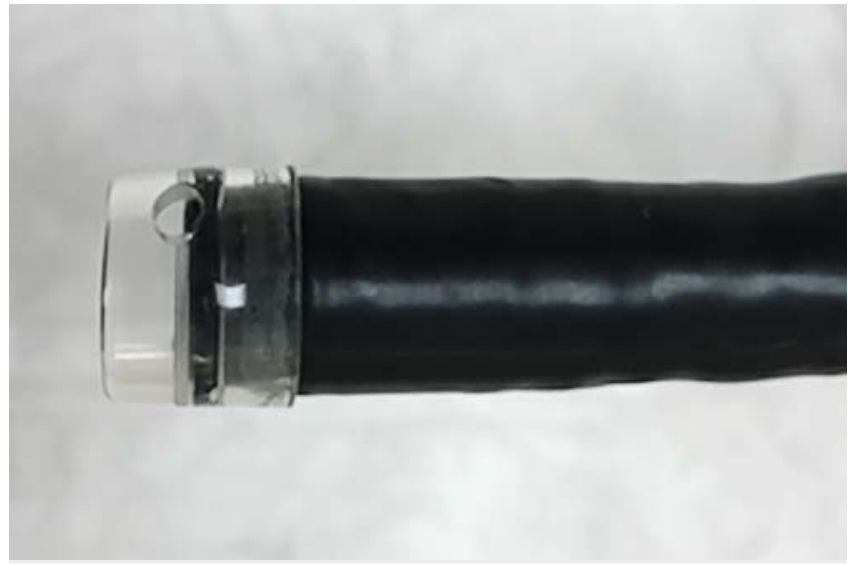

Fig. 1 Transparent cap fixed to the end of a colonoscope.

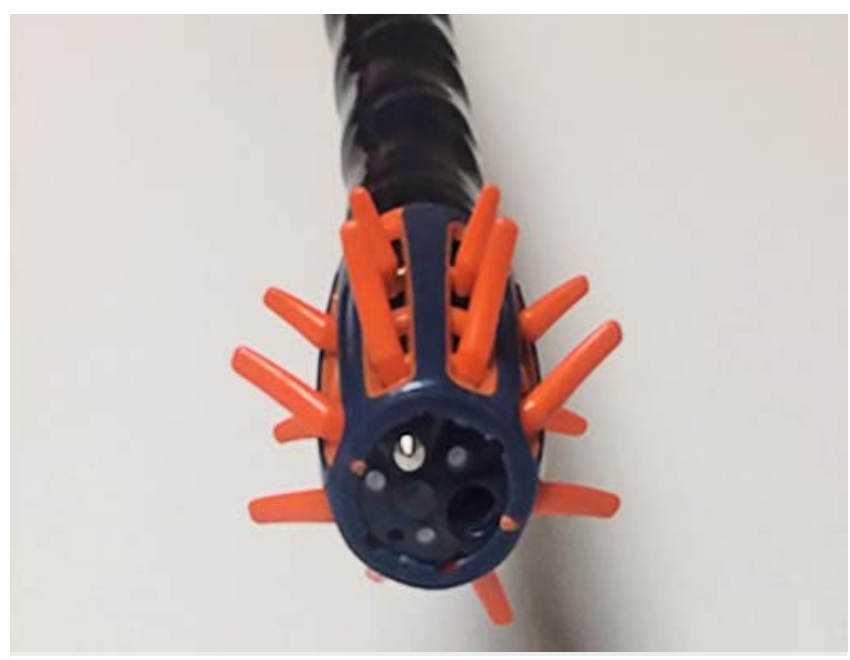

Fig. 2 Endocuff with two rows of soft projections fixed to the end of a colonoscope.

randomization, the colonoscopes were either fitted with no distal attachment, Olympus 4-mm transparent cap (Olympus Medical Systems, Tokyo, Japan) or Endocuff (Arc Medical, Leeds, England) prior to colonoscope insertion. Bowel prep was graded using the Boston Bowel Preparation Scale (BBPS). Proximal colon was defined as colon segment proximal to the splenic flexure. Distal colon included splenic flexure and beyond. Polyp removal was by cold forceps, cold snare, or hot snare per endoscopists' discretion. All specimens were analyzed by three experienced gastrointestinal pathologists. Polyp size was as per specimen measurements in the pathology report. When fragmented, the sum of individual fragment sizes determined polyp size.

\section{Outcomes}

The primary outcome was adenoma detection rate (ADR). Secondary outcomes were proximal ADR, total number of polyps detected, sessile serrated adenoma detection rate (SSADR), mean number of adenomas per colonoscopy (APC), mean adenoma per positive colonoscopy (APPC), cecal intubation rate, 
cecal intubation time, withdrawal time, and major complications. ADR was defined as proportion of patients with at least one tubular adenoma. APC was defined as the total number of adenomas divided by the number of colonoscopies performed. APPC was defined as the total number of adenomas divided by the total of colonoscopies where at least one adenoma was discovered.

\section{Statistical analysis}

The required sample size of 126 (42 patients per arm) was estimated for a logistic regression model with the three-category treatment variable as the predictor and an expected $30 \%$ increase in ADR for the transparent cap and Endocuff attachments over the control ADR of $25 \%$ to achieve a power of $80 \%$. Chi square tests examined differences in gender, smoking status, diabetes, BBPS and procedure indication, between treatment arms. Normality for the continuous variables was assessed using histograms and quantiles. Alcoholic drinks per week was non-normal and tested using the Kruskal-Wallis test. All other continuous variables were approximately normal. ANOVAs were used to test for differences between the treatment group and the variables age, body-mass index, time to cecum, withdrawal time, and number of adenomas. Differences in ADR, proximal ADR, distal ADR, and SSADR were determined using chi square tests. Difference in polyp location, size, and type by treatment arm were analyzed using mixed effects regressions to control for multiple polyps per patient, and were reported as odds ratios for type and location, and as least squares means for size. Mixed effects models were fit with a random intercept and treatment as a fixed effect. We did not control for clustering within endoscopist. Categorical variables were described by frequency counts and percentages. Quantitative variables were described by mean and standard deviations. $P<0.05$ was considered statistically significant. For procedure outcomes we conducted a correction to control the false discovery rate and reported the estimated q-values [20]. All statistical analyses were performed by MDW, an experienced statistician using SAS software version 9.4 (SAS Institute, Cary, North Carolina, United States).

\section{Results}

\section{Patient characteristics}

A total of 126 study patients, 42 per arm, underwent colonoscopy between March 2016 and January 2017. All enrolled subjects were included in the final analysis ( $\mathbf{F i g . 3}$ ). Patient demographics and baseline characteristics were similar across treatment groups ( $\vee$ Table $\mathbf{1})$.

\section{Procedure characteristics}

BBPS and procedure indication were similar among groups $(P=$ 0.54 and $P=0.27$, respectively) ( $\triangleright$ Table 2 ). Cecal intubation was $100 \%$ in all groups, and intubation time was similar in the SC, CAC and EAC arms at 5.6, 6 and 6.1 minutes respectively $(P=0.77)$. Average withdrawal time was also similar in SC, CAC and EAC groups at $12.9,12.4$ and 13.0 minutes respectively $(P=$ 0.86) ( Table 2).

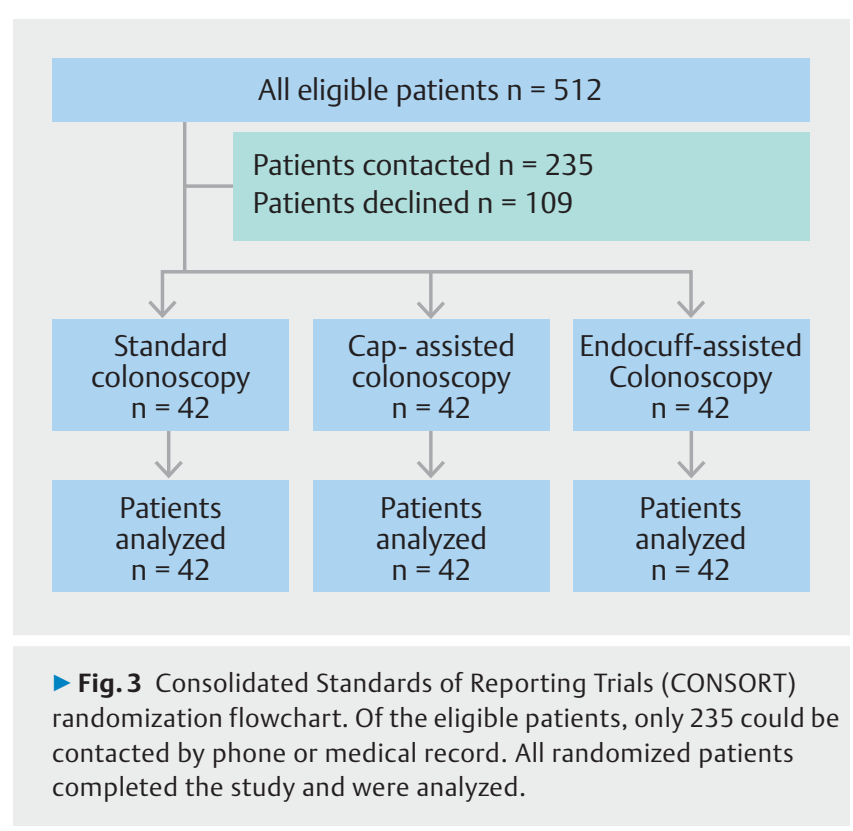

\section{Polyp detection}

Overall, there was a significant difference in the total number of polyps detected between the three treatment arms $(P=0.017$, $q=0.12)$. Both EAC (OR 4.6; $95 \% \mathrm{Cl}[1.5-14.5])$ and SC (OR 3.6; $95 \% \mathrm{Cl}[1.1-11.3])$ had significantly greater odds of detecting more polyps than CAC. EAC had no significant difference in polyp detection compared to SC (OR 1.29, $95 \% \mathrm{Cl}[0.4-$ 4.24]). There was no significant difference in polyp detection rates between the proximal or distal regions of the colon between the groups $(P=0.9)$. There was no significant difference in mean size of polyps detected between the groups (SC 4.4 mm, CAC $5.2 \mathrm{~mm}$, EAC $4.8 \mathrm{~mm} ; P=0.5$ ) ( Table 3).

\section{Adenoma detection rate}

There was no significant difference in overall ADR, proximal ADR, distal ADR, or SSADR ( Table 3). ADR was $52.4 \%, 40.5 \%$ and $54.8 \%$ in the SC, CAC and EAC groups $(P=0.37)$. Proximal ADR showed a similar trend at $45 \%, 35 \%$, and $50 \%$ in each group $(P=0.41)$. There was no difference in distal ADR across groups with $26.2 \%, 11.9 \%$, and $23.8 \%$ in SC, CAC, and EAC groups, respectively $(P=0.22)$. SSA detection rate was also similar at $16 \%, 14 \%$, and $23 \%$ respectively $(P=0.50)(\triangleright$ Table 3$)$. There was a numeric difference between EAC and CAC among all ADR outcomes, but it was not significant ( $\triangleright$ Table 3 ).

\section{Adenomas}

The mean number of adenomas per colonoscopy was $1.17,0.76$ and 1.7 in the SC, CAC and EAC groups ( $\triangleright$ Table 3 ). There was no significant difference in the means when comparing either device to non-device assisted screening colonoscopy (SC); however, EAC demonstrated a significantly higher mean adenoma per colonoscopy compared to CAC ( 1.7 vs. $0.76 ; P=0.01$ ) ( $\triangleright$ Table 3). When analyzing adenomas per positive colonoscopy, there was no difference between the three groups (SC 2.08 vs. CAC 1.63 vs EAC 2.6; $P=0.21$ ) ( $\triangleright$ Table 3 ). 
- Table 1 Patient demographics and baseline characteristics.

\begin{tabular}{|c|c|c|c|c|}
\hline & $\begin{array}{l}\text { SC } \\
n=42\end{array}$ & $\begin{array}{l}\text { CAC } \\
n=42\end{array}$ & $\begin{array}{l}\text { EAC } \\
n=42\end{array}$ & $P^{1}$ \\
\hline Gender & & & & 0.97 \\
\hline - Men, n (\%) & $23(54.8)$ & $24(57.1)$ & $23(54.8)$ & \\
\hline - Women, n (\%) & $19(45.2)$ & $18(42.9)$ & $19(45.2)$ & \\
\hline Age, mean $\pm s d$ & $59.3 \pm 7.4$ & $60.0 \pm 6.7$ & $60.0 \pm 6.8$ & 0.87 \\
\hline $\mathrm{BMI}$, mean $\pm \mathrm{sd}$ & $28.5 \pm 4.3$ & $28.3 \pm 5.5$ & $27.4 \pm 5.4$ & 0.54 \\
\hline $\begin{array}{l}\text { Smoking Status, } \\
\mathrm{n}(\%)\end{array}$ & & & & 0.71 \\
\hline - Never smoker & $30(71.5)$ & $24(57.1)$ & $28(66.7)$ & \\
\hline - Former smoker & $11(26.1)$ & $16(38.1)$ & $13(30.9)$ & \\
\hline - Current smoker & $1(2.4)$ & $2(4.8)$ & $1(2.4)$ & \\
\hline $\begin{array}{l}\text { Alcoholic drinks } \\
\text { per week, } \\
\text { mean } \pm \text { sd }\end{array}$ & $4.0 \pm 3.6$ & $6.8 \pm 10.7$ & $4.4 \pm 4.0$ & 0.86 \\
\hline Diabetes, n (\%) & $4(9.5)$ & $3(7.1)$ & $5(11.9)$ & 0.76 \\
\hline Race, n (\%) & & & & 0.40 \\
\hline - White & $31(73.8)$ & $33(78.5)$ & $32(76.2)$ & \\
\hline $\begin{array}{l}\text { - African-Ameri- } \\
\text { can }\end{array}$ & $1(2.4)$ & $1(2.4)$ & $1(2.4)$ & \\
\hline - Hispanic & $5(11.9)$ & $1(2.4)$ & $3(7.1)$ & \\
\hline - Asian & $3(7.1)$ & $1(2.4)$ & $2(4.8)$ & \\
\hline - Other & 0 & $1(2.4)$ & $3(7.1)$ & \\
\hline - Unknown² & $2(4.8)$ & $5(11.9)$ & $1(2.4)$ & \\
\hline \multicolumn{5}{|c|}{$\begin{array}{l}\text { SC, standard colonoscopy; CAC, cap-assisted colonoscopy; EAC, Endocuff- } \\
\text { assisted colonoscopy; BMI, body mass index. } \\
\text { 'Chi-square was used to determine significance with respect to gender, } \\
\text { race, smoking, and diabetes between groups. ANOVA was used to deter- } \\
\text { mine significance in age, BMI and the Kruskal-Wallis test was used to test } \\
\text { for differences in alcohol consumption between groups. P.05 was consid- } \\
\text { ered significant. } \\
{ }^{2} \text { Classified as "unknown" if patient declined to state or if unavailable from } \\
\text { the medical record }\end{array}$} \\
\hline
\end{tabular}

\section{Complications and adverse events}

Two patients in the Endocuff arm developed post-polypectomy bleeding and required repeat colonoscopy to achieve hemostasis.

\section{Discussion}

This is the first randomized study to compare both CAC and EAC to $\mathrm{SC}$. We found no significant improvement with either device compared to SC with respect to ADR, proximal and distal ADR, SSADR, mean adenoma per procedure and mean adenomas per positive colonoscopy. Both EAC and SC detected a greater number of polyps than CAC, and EAC demonstrated a significantly higher mean adenoma per procedure compared to CAC. However, when this was corrected to control for the false-discovery rate, these did not reach statistical significance. Overall there
- Table2 Procedure characteristics.

\begin{tabular}{|l|l|l|l|l|}
\hline SC & CAC & EAC & $P^{*}$ \\
\hline$n=42$ & $n=42$ & $n=42$ & \\
\hline
\end{tabular}

Indication, $\mathrm{n}(\%)$

0.29

\begin{tabular}{|l|l|l|l|l|}
\hline - Screening & $27(64.3)$ & $32(76.2)$ & $33(78.5)$ & \\
\hline - Surveillance & $15(35.7)$ & $10(23.8)$ & $9(21.5)$ & \\
\hline $\begin{array}{l}\text { Boston Bowel Prep } \\
\text { Score, mean } \pm \text { sd }\end{array}$ & $8.9 \pm 0.5$ & $8.9 \pm 0.5$ & $8.9 \pm 0.3$ & 0.54 \\
\hline $\begin{array}{l}\text { Withdrawal time } \\
\text { (12.9 }\end{array}$ & 12.2 & $12.4 \pm 5.6$ & $13.0 \pm 6.2$ & 0.86 \\
\hline
\end{tabular}

(minutes),

mean $\pm s d$

\begin{tabular}{|l|l|l|l|l|}
\hline Time to cecum & $5.6 \pm 3.8$ & $6.0 \pm 2.8$ & $6.1 \pm 3.3$ & 0.77 \\
\hline
\end{tabular}

(minutes),

mean $\pm s d$

SC, standard colonoscopy; CAC, cap-assisted colonoscopy; EAC, Endocuffassisted colonoscopy.

* Chi-square test used to determine differences in procedure indication and Boston bowel prep score between groups. A mixed effects ANOVA used to determine significance in withdrawal and cecum times between groups. $P$ .05 was considered significant.

was a trend towards EAC being better than CAC in all study metrics without reaching statistical significance.

Current American Society for Gastrointestinal Endoscopy and American College of Gastroenterology screening guidelines for average-risk patients recommend an overall ADR of $25 \%, 30 \%$ for men and $20 \%$ for women [21]. In our study, all treatment arms demonstrated a higher-than-recommended $A D R$, indicating that all patients received a high-quality examination regardless of attachment.

Previous ADR studies with CAC have shown mixed results compared to SC $[10,12,14,15,22-24]$. Most earlier studies included patients outside of the average-risk colon cancer screening age range, and indications not just limited to CRC screening or colon adenoma surveillance. A large meta-analysis carried out by $\mathrm{Ng}$ and colleagues analyzed 12 randomized studies comparing CAC to $\mathrm{SC}$, and found that $\mathrm{CAC}$ was superior to $S C$ in detecting all polyps, but there were no difference in $A D R$ [13].

Previous studies comparing EAC to SC have shown a more consistent improvement in ADR than those of CAC. EAC has shown to increase overall polyp detection rate, ADR and higher adenomas per patient compared to standard therapy $[17,19$, 25]. But these studies contained a large number of diagnostic and surveillance colonoscopies, which makes it difficult to generalize to an average-risk screening population. A recent metaanalysis by Chin et al examined eight retrospective and randomized studies and found a significantly higher ADR with EAC compared to SC [26]. Moreover, a tandem colonoscopy study found that EAC detected $20 \%$ more adenomas compared to SC [18]. Tandem colonoscopy studies report adenoma miss rates up to $25 \%$, which could lead to interval CRC [27]. Hence, EAC may help with reducing interval CRC, but more long-term follow-up studies are needed. 
Table 3 Procedure outcomes.

\begin{tabular}{|c|c|c|c|c|c|}
\hline & $\begin{array}{l}\text { SC } \\
n=42\end{array}$ & $\begin{array}{l}\text { CAC } \\
n=42\end{array}$ & $\begin{array}{l}\text { EAC } \\
n=42\end{array}$ & $P^{1}$ & $Q^{2}$ \\
\hline Adenoma detection rate (ADR), $\mathrm{n}(\%)$ & $22(52.4)$ & $17(40.5)$ & $23(54.8)$ & 0.37 & .54 \\
\hline - Proximal ${ }^{3}$ ADR, n (\%) & $19(45.2)$ & $15(35.7)$ & $21(50.0)$ & 0.41 & .54 \\
\hline - Distal ${ }^{4}$ ADR, n (\%) & $11(26.2)$ & $5(11.9)$ & $10(23.8)$ & 0.22 & .51 \\
\hline SSA detection rate, $\mathrm{n}(\%)$ & $7(16.7)$ & $6(14.3)$ & $10(23.8)$ & 0.50 & .54 \\
\hline Adenoma mean size $(\mathrm{mm})$, mean $\pm \mathrm{SD}$ & $4.44 \pm 0.4$ & $5.20 \pm 0.5$ & $4.75 \pm 0.4$ & 0.54 & .54 \\
\hline Mean adenoma per colonoscopy (APC) & $1.17 \pm 1.3$ & $0.76 \pm 1.2$ & $1.7 \pm 2.3$ & 0.03 & .21 \\
\hline Mean adenoma per positive colonoscopy (APPC) & $2.08 \pm 1.1$ & $1.63 \pm 1.4$ & $2.6 \pm 2.4$ & 0.21 & .51 \\
\hline \multicolumn{6}{|c|}{$\begin{array}{l}\text { SC, standard colonoscopy; CAC, cap-assisted colonoscopy; EAC, Endocuff-assisted colonoscopy; SSA, sessile serrated adenoma } \\
1 \text { Included all adenomas proximal to the splenic flexure } \\
2 \text { Included all adenomas distal to the splenic flexure } \\
{ }^{3} \text { Chi-square test was performed to determine significance for overall ADR, ADR by location and SSADR. A mixed-effects ANOVA was used to determine differences in } \\
\text { adenoma size between treatment arms. An ANOVA was fit using all colonoscopies to test for differences in APC and APPC between the treatment arms. A P-value of } \\
.05 \text { was considered significant. } \\
{ }^{4} \text { Adjusted p-value controlling for the false discovery rate. }\end{array}$} \\
\hline
\end{tabular}

We found no difference in ADR between SC and EAC. Given the high ADR in the control group, we retrospectively reviewed the pre-study ADR of each endoscopist and found that the baseline ADR was $43 \%, 48 \%$ and $55 \%$, respectively. Based on the high pre-study ADR and large effect size, our study was likely underpowered to detect a significant difference between the groups. Moreover, our results may also indicate that adding the Endocuff confers no additional benefit for high adenoma detectors.

Interestingly we noted CAC to underperform SC among all endoscopists in all metrics including ADR, despite similar baseline and procedure characteristics. There have been no published studies establishing a learning curve with the transparent cap but there appears to be some benefit with successive use [28]. A pre-study training period with transparent cap has also varied between three and 20 in previous studies $[10,14,15]$. We did not employ pre-study training, and the study endoscopists did not routinely use the transparent cap in their practices. Though unclear, relative inexperience and technical challenges could account for the lower ADR in the CAC group.

Improvement in proximal ADR is an area of great interest. The proximal colon poses challenges for adenoma detection due to more prominent haustrae, flat and/or subtler lesions, and differences in bowel prep. Missed adenomas are more likely in the proximal colon, and may explain the higher protective effect of screening colonoscopy against cancer in the distal colon [5, 29-31]. Devices that can increase detection of adenomas in the proximal colon may be of substantial benefit. We found no difference between EAC and SC in proximal ADR. There was a trend towards both outperforming CAC in the proximal colon. $A$ recent meta-analysis found that the transparent cap detected more proximal adenomas per patient compared to standard colonoscopy, and the adenomas tended to be diminutive [32]. EAC has also demonstrated an increased ADR in the cecum and ascending colon in earlier studies, and higher odds of proximal adenoma detection $[17,19,26]$. To date, there have been no EAC or CAC studies to our knowledge with proximal ADR as a primary endpoint.

We also examined differences in SSADR. SSA have a predilection for the proximal colon and may be harder to detect due to more subtle features [33-36]. Retrospective studies report varying prevalence of SSAs between $4 \%$ to $13 \%$, and higher SSADR has a stronger correlation with the endoscopist versus other factors such as age and gender [37-40]. Based on an overall ADR of $20 \%$, it is thought that corresponding SSADR should be $5 \%$ [38]. We found that in all three groups, SSADR exceeded this threshold, which likely corresponds to our endoscopists' overall high ADR. While EAC demonstrated a higher SSADR compared to SC and CAC, this was not statistically significant. A meta-analysis of three studies by Desai et al suggested that CAC may detect more SSAs than standard colonoscopy [32]. Our data suggests that EAC may improve SSA detection. Adequately powered studies in the future may help determine if either EAC or CAC are superior to SC in terms of SSADR.

APC and mean APPC are additional quality metrics for screening colonoscopy given limitations of ADR [41-43]. APC may correlate well with endoscopists who are high detectors, while APPC may have more correlation over a wide range of ADR [42]. Higher APC and APPC likely correlate with a more thorough exam. When uncorrected for the false discovery rate, we found that EAC had a significantly better APC than CAC, and detected $46 \%$ more adenomas per procedure (1.7 vs. 1.17) compared to SC but was not statistically significant. Similar findings but to a lesser magnitude were noted with APPC, where EAC detected $49 \%$ and $17 \%$ more adenomas per positive colonoscopy than CAC and SC, respectively. Our study was not adequately powered to detect these differences, but it does suggest that EAC may detect more adenomas in patients with at least one adenoma.

There was no difference in mean adenoma size between the groups, probably because mean adenoma size in all groups was diminutive. While some earlier studies have indicated higher 
detection and lower miss rates for diminutive adenomas using either EAC or CAC, others have shown no difference $[10,11$, $17-19,24,25,44,45]$.

Two study patients developed post-polypectomy bleeding after undergoing EAC, which is unlikely to be related to the device. While prior studies reported higher risk of minor mucosal tearing due to the double row of projections of endocuff, we did not observe this $[17,19]$.

There are limitations to our study. First, it was single-center study with a relatively small sample size. Our endoscopists were not blinded, but this was likely not a significant factor given the lack of statistically significant differences in ADR between treatment groups. Our high pre-study ADR and sample size calculated to detect a $30 \%$ difference in the primary endpoint of ADR likely prevented us from detecting a statistically significant difference between groups. We were not able to study if the transparent cap or the Endocuff may improve ADR among trainees or endoscopists with lower than recommended ADR. By measuring polyp size based on specimen measurements in the pathology lab, we may have underestimated polyp size due to tissue shrinkage in formalin.

The strengths of our study reside in its prospective randomized controlled design, outpatient setting, inclusion of only screening and surveillance colonoscopies, split-dose bowel preparation, and uniformly excellent prep quality. Withdrawal times were on average twice the recommended duration of 6 minutes in all arms, though it should be noted that the time taken to perform polypectomy is included within the withdrawal time [21]. Study population was inclusive of both genders, and all major races/ethnicities. Moreover, our subjects and procedure indications are applicable to the majority of gastroenterology practices in the Western world.

During our clinical trial, Endocuff was replaced by a newer version called Endocuff Vision, which has a single row of slightly longer finger-like projections. In a recent non-randomized study of fecal immunochemical test-positive patients, endoscopists found a higher mean ADR with Endocuff Vision [46]. But a randomized UK study found no difference in ADR between Endocuff Vision and standard colonoscopy [47]. The ADR was $63 \%$ in the SC arm, suggesting limited benefit of endocuff when ADR is already high.

A decision to use any device to increase ADR should consider the potential benefit and overall cost of intervention. To date, no cost-benefit analysis has been performed on either CAC or EAC.

\section{Conclusion}

In conclusion, we presented the first randomized study to compare two popular distal colonoscope attachments, the transparent cap and Endocuff, with SC, and found no significant benefit with either device over a good-quality SC by experienced endoscopists. Future studies may help determine if either device confers a benefit in ADR, especially among low adenoma detectors.

\section{Acknowledgements}

The project described was supported by the National Center for Advancing Translational Sciences, National Institutes of Health, through grant number UL1 TR001860. The content is solely the responsibility of the authors and does not necessarily represent the official views of the NIH.

\section{Competing interests}

None

\section{References}

[1] Siegel RL, Miller KD, Jemal A. Cancer Statistics, 2017. CA Cancer J Clin 2017; 67: 7-30

[2] Sonnenberg A, Byrd-Clark DD. U.S. hospitalizations for colorectal cancer 1970-2010. Dig Dis Sci 2014; 59: 282-286

[3] Zauber AG, Winawer SJ, O'Brien M] et al. Colonoscopic polypectomy and long-term prevention of colorectal-cancer deaths. N Engl J Med 2012; 366: 687-696

[4] Siegel RL, Miller KD, Fedewa SA et al. Colorectal cancer statistics, 2017. CA Cancer J Clin 2017; 67: 177-193

[5] Laiyemo AO, Doubeni C, Sanderson AK et al. Likelihood of missed and recurrent adenomas in the proximal versus the distal colon. Gastrointest Endosc 2011; 74: 253-261

[6] Corley DA, Jensen CD, Marks AR et al. Adenoma detection rate and risk of colorectal cancer and death. N Engl J Med 2014; 370: 1298 1306

[7] Kaminski MF, Regula J, Kraszewska E et al. Quality indicators for colonoscopy and the risk of interval cancer. N Engl J Med 2010; 362: $1795-1803$

[8] Kaminski MF, Wieszczy P, Rupinski M et al. Increased rate of adenoma detection associates with reduced risk of colorectal cancer and death. Gastroenterology 2017; 153: 98 - 105

[9] Dik VK, Moons LM, Siersema PD. Endoscopic innovations to increase the adenoma detection rate during colonoscopy. World J Gastroenterol 2014; 20: 2200-2211

[10] de Wijkerslooth TR, Stoop EM, Bossuyt PM et al. Adenoma detection with cap-assisted colonoscopy versus regular colonoscopy: a randomised controlled trial. Gut 2012; 61: 1426-1434

[11] Kim DJ, Kim HW, Park SB et al. Efficacy of cap-assisted colonoscopy according to lesion location and endoscopist training level. World J Gastroenterol 2015; 21: $6261-6270$

[12] Lee YT, Lai LH, Hui A] et al. Efficacy of cap-assisted colonoscopy in comparison with regular colonoscopy: a randomized controlled trial. Am J Gastroenterol 2009; 104: 41-46

[13] Ng SC, Tsoi KK, Hirai HW et al. The efficacy of cap-assisted colonoscopy in polyp detection and cecal intubation: a meta-analysis of randomized controlled trials. Am J Gastroenterol 2012; 107: 1165-1173

[14] Pohl H, Bensen SP, Toor A et al. Cap-assisted colonoscopy and detection of Adenomatous Polyps (CAP) study: a randomized trial. Endoscopy 2015; 47: $891-897$

[15] Rastogi A, Bansal A, Rao DS et al. Higher adenoma detection rates with cap-assisted colonoscopy: a randomised controlled trial. Gut 2012; 61: $402-408$

[16] Westwood DA, Alexakis N, Connor SJ. Transparent cap-assisted colonoscopy versus standard adult colonoscopy: a systematic review and meta-analysis. Dis Colon Rectum 2012; 55: 218-225 
[17] Biecker E, Floer M, Heinecke A et al. Novel endocuff-assisted colonoscopy significantly increases the polyp detection rate: a randomized controlled trial. J Clin Gastroenterol 2015; 49: 413-418

[18] De Palma GD, Giglio MC, Bruzzese D et al. Cap cuff-assisted colonoscopy versus standard colonoscopy for adenoma detection: a randomized back-to-back study. Gastrointest Endosc 2018; 87: 232 240

[19] Floer M, Biecker E, Fitzlaff R et al. Higher adenoma detection rates with endocuff-assisted colonoscopy - a randomized controlled multicenter trial. PLoS One 2014; 9: e114267

[20] Benjamini Y, Hochberg Y. Controlling the false discovery rate: a practical and powerful approach to multiple testing. J Royal Statist Soc Series B (Methological) 1995; 57: 289-300

[21] Rex DK, Schoenfeld PS, Cohen J et al. Quality indicators for colonoscopy. Gastrointest Endosc 2015; 81: 31-53

[22] Tee HP, Corte C, Al-Ghamdi $\mathrm{H}$ et al. Prospective randomized controlled trial evaluating cap-assisted colonoscopy vs standard colonoscopy. World J Gastroenterol 2010; 16: 3905-3910

[23] Kondo S, Yamaji Y, Watabe $\mathrm{H}$ et al. A randomized controlled trial evaluating the usefulness of a transparent hood attached to the tip of the colonoscope. Am J Gastroenterol 2007; 102: 75-81

[24] Harada $\mathrm{Y}$, Hirasawa D, Fujita $\mathrm{N}$ et al. Impact of a transparent hood on the performance of total colonoscopy: a randomized controlled trial. Gastrointest Endosc 2009; 69: 637 -644

[25] van Doorn SC, van der Vlugt M, Depla A et al. Adenoma detection with Endocuff colonoscopy versus conventional colonoscopy: a multicentre randomised controlled trial. Gut 2017; 66: 438-445

[26] Chin M, Karnes W, Jamal MM et al. Use of the Endocuff during routine colonoscopy examination improves adenoma detection: A meta-analysis. World J Gastroenterol 2016; 22: 9642 - 9649

[27] le Clercq CM, Bouwens MW, Rondagh EJ et al. Postcolonoscopy colorectal cancers are preventable: a population-based study. Gut 2014; 63: $957-963$

[28] Tang Z, Zhang DS, Thrift AP et al. Impact of cap-assisted colonoscopy on learning curve and quality in colonoscopy: a randomized controlled trial. Gastrointest Endosc 2018; 87: 723 - 732

[29] Singh H, Nugent Z, Demers AA et al. The reduction in colorectal cancer mortality after colonoscopy varies by site of the cancer. Gastroenterology 2010; 139: $1128-1137$

[30] Nishihara R, Wu K, Lochhead P et al. Long-term colorectal-cancer incidence and mortality after lower endoscopy. N Engl J Med 2013; 369: $1095-1105$

[31] Jacob B], Moineddin R, Sutradhar R et al. Effect of colonoscopy on colorectal cancer incidence and mortality: an instrumental variable analysis. Gastrointest Endosc 2012; 76: 355- 64 e1

[32] Desai M, Sanchez-Yague A, Choudhary A et al. Impact of cap-assisted colonoscopy on detection of proximal colon adenomas: systematic review and meta-analysis. Gastrointest Endosc 2017; 86: 274-281
[33] Yang JF, Tang S], Lash RH et al. Anatomic distribution of sessile serrated adenoma/polyp with and without cytologic dysplasia. Arch Pathol Lab Med 2015; 139: 388-393

[34] Murakami T, Sakamoto N, Ritsuno H et al. Distinct endoscopic characteristics of sessile serrated adenoma/polyp with and without dysplasia/carcinoma. Gastrointest Endosc 2017; 85: 590 - 600

[35] Gurudu SR, Heigh RI, De Petris G et al. Sessile serrated adenomas: demographic, endoscopic and pathological characteristics. World J Gastroenterol 2010; 16: 3402-3405

[36] Buda A, De Bona M, Dotti I et al. Prevalence of different subtypes of serrated polyps and risk of synchronous advanced colorectal neoplasia in average-risk population undergoing first-time colonoscopy. Clin Transl Gastroenterol 2012; 3: e6

[37] Ross WA, Thirumurthi S, Lynch PM et al. Detection rates of premalignant polyps during screening colonoscopy: time to revise quality standards? Gastrointest Endosc 2015; 81: 567 - 574

[38] Kahi C], Li X, Eckert G] et al. High colonoscopic prevalence of proximal colon serrated polyps in average-risk men and women. Gastrointest Endosc 2012; 75: 515-520

[39] Kahi C], Hewett DG, Norton DL et al. Prevalence and variable detection of proximal colon serrated polyps during screening colonoscopy. Clin Gastroenterol Hepatol 2011; 9: 42-46

[40] Anderson JC, Butterly LF, Goodrich M et al. Differences in detection rates of adenomas and serrated polyps in screening versus surveillance colonoscopies, based on the new hampshire colonoscopy registry. Clin Gastroenterol Hepatol 2013; 11: $1308-1312$

[41] Wang HS, Pisegna J, Modi R et al. Adenoma detection rate is necessary but insufficient for distinguishing high versus low endoscopist performance. Gastrointest Endosc 2013; 77: 71 - 78

[42] Lee T], Rutter MD, Blanks RG et al. Colonoscopy quality measures: experience from the NHS Bowel Cancer Screening Programme. Gut 2012; 61: $1050-1057$

[43] Kahi C], Vemulapalli KC, Johnson CS et al. Improving measurement of the adenoma detection rate and adenoma per colonoscopy quality metric: the Indiana University experience. Gastrointest Endosc 2014; 79: $448-454$

[44] Horiuchi A, Nakayama Y, Kajiyama M et al. Benefits and limitations of cap-fitted colonoscopy in screening colonoscopy. Dig Dis Sci 2013; 58: $534-539$

[45] Hewett DG, Rex DK. Cap-fitted colonoscopy: a randomized, tandem colonoscopy study of adenoma miss rates. Gastrointest Endosc 2010; 72: $775-781$

[46] Tsiamoulos ZP, Misra R, Rameshshanker R et al. Impact of a new dista attachment on colonoscopy performance in an academic screening center. Gastrointest Endosc 2018; 87: 280-287

[47] Bhattacharyya R, Chedgy F, Kandiah K et al. Endocuff-assisted vs. standard colonoscopy in the fecal occult blood test-based UK Bowel Cancer Screening Programme (E-cap study): a randomized trial. Endoscopy 2017; 49: $1043-1050$ 